\title{
Evaluation of Frailty Elderly Syndrome, General Health and Cognitive Disorders in the Elderly and Their Relationship with Demographic Factors and Underlying Diseases
}

\author{
HAMID TAGHINEJAD ${ }^{1}$, SATTAR KIKHAVANI ${ }^{2}$, SARA MOHAMMAD NEJAD ${ }^{3}$, NAFISEH SOHRABI ${ }^{* 4}$ \\ ${ }^{1}$ Associate Professor, Department of Nursing, Faculty of Nursing and Midwifery, Ilam University of Medical Sciences, Ilam, IR Iran. \\ ${ }^{2}$ Professor of clinical psychology, Ilam University of Medical Sciences, Ilam, Iran \\ ${ }^{3}$ Faculty members, Department of Medical and Surgical Nursing, School of Nursing and Midwifery, Ilam University of Medical Sciences, Ilam, \\ Iran \\ ${ }^{4} \mathrm{MSc}$ Student of Nursing, Department of Nursing, Ilam University of Medical Sciences, Ilam, Iran. \\ Corresponding author: Nafiseh Sohrabi
}

\begin{abstract}
Introduction: Due to the vulnerability of the elderly in the community and the increase in their population and the problems occurring due to aging in the elderly, the present study aimed to investigate the frailty elderly syndrome, general health and cognitive disorders in the elderly in llam in 2020.

Materials and Methods: This cross-sectional study was performed on 267 elderly referring to teaching hospitals in Ilam. Data collection tools were GHQ-28, MMSE and Edmonton questionnaires. Data were analyzed using SPSS v.24 statistical software using independent t-test, chi-square, Fisher's exact test, one-way and two-way analysis of variance, Mann-Whitney, Kruskal-Wallis and linear regression.

Results: The mean \pm standard deviation of the overall score of general health, frailty elderly syndrome and cognitive disorders in the studied elderly were $44.38 \pm 13.43,9.29 \pm 2.98$ and $23.40 \pm 6.49$, respectively. There was a statistically significant relationship between cognitive disorders with age, marital status, education and underlying diseases and also between frailty elderly syndrome with age, marital status, place of residence, gender, education, type of insurance and some underlying diseases $(P<0.001)$. There was a significant relationship between general health of the elderly and pulmonary disease $(P=0.03)$.

Conclusion: The general health of the elderly was low so that most of the elderly suffered from mild symptoms, the greatest effect was related to depression and then anxiety (psychological dimension). Regarding cognitive disorders, a large number of patients did not have any pathological disorders. The rate of frailty elderly syndrome was high in the study population.
\end{abstract}

Keywords: frailty elderly syndrome, Cognitive disorders, General health

\section{INTRODUCTION}

According to the definition of the World Health Organization, people over 60 are called elderly (1). In fact, aging is a decrease in mental and physical strength that occurs over time (2). Demographic change led to an increase in the number of elderly people in developing and developed countries. Between 2000 and 2050, the proportion of people aged 60 and over in the world is projected to increase from $11 \%$ to $22 \%$, and the number of elderly will increase from 605 million to 2 billion and also, the number of elderly people over 80 will quadruple (3). According to the 2011 census, the number of elderly people in Iran has increased from 6159676 (8.2\% of the total population) to 7414091 ( $9.3 \%$ of the total population) in 2016. The number of elderly people is increasing in all countries of the world, including Iran $(4,5)$. Physical and cognitive deficiencies are among the consequences of aging; some of the deficiencies that have attracted the attention of specialists are cognitive disorders of the elderly and subsequent decline in their general health, which is a common problem in this period (6). Other deficiencies include frailty elderly syndrome, which is a very common syndrome in the elderly and leads to an increased risk of various diseases, deaths and decreased life expectancy. Characteristics of frailty elderly syndrome include weakness, weight loss and low activity, which are associated with adverse health consequences (7). Frailty elderly syndrome is a common aging disease with an average prevalence of $10 \%$ (8).

According to the Centers for Disease Control and Prevention, the incidence of cognitive disorder in the elderly is so high that for every 8 elderly, 1 elderly person has confusion disorder and memory loss (9). Evidence from other studies suggests that frailty may increase the risk of mild cognitive disorder in the future (8). According to studies conducted in Iran, about $5 \%$ of the elderly suffer from severe cognitive disorder, $47.5 \%$ suffer from moderate cognitive disorder, $30 \%$ have mild cognitive disorder and only $17.5 \%$ did not have cognitive disorder (10). So far, no study is conducted to measure the rate of aging in Iran, so the present study aimed to investigate the frailty elderly syndrome, general health and cognitive disorders in the elderly referring to educational hospitals in Ilam in 2020 and the relationship between them and demographic factors and underlying diseases were assessed.

\section{METHOD}

This is a cross-sectional study that was performed on 267 elderly people aged 60 years and older referring to Imam Khomeini and Mostafa Khomeini hospitals in llam in 2020. Inclusion criteria were 60 years of age and above, the ability to speak and communicate, and hospitalization for more than 6 hours in one of the hospitals of Imam Khomeini and Mostafa Khomeini. Exclusion criteria were the death of the elderly, the unwillingness of the elderly to 
continue to cooperate or to undergo treatment that was painful or annoying for the elderly. The sample size was calculated using the following formula with 95\% confidence interval, 0.06 error and $50 \%$ prevalence.

$$
\mathrm{n}=\frac{\mathrm{z}^{2} \mathrm{p} \mathrm{q}}{\mathrm{d}^{2}}
$$

The samples were selected in a stratified and clustered manner from among the elderly aged 60 years and older referring to the educational hospitals of Ilam city, so that the educational hospitals were selected as a class and in each hospital, 2 wards were randomly selected as the cluster and the necessary samples were selected from the elderly referring to the selected wards.

Data collection tools: In the present study, 3 questionnaires of GHQ-28 (General Health Quastiannar28), Mini-Mental State Exam (MMSE) and Edmonton were used to collect the required data in the form of face-to-face interviews. One of the most common tools available in identifying health-related problems in the elderly is the GHQ questionnaire which includes 4 subscales of physical symptoms, symptoms of anxiety and sleep disorders, social action and depression, and each subscale includes 7 questions that for sum, the score of $A$ was assigned to the score of $0, B$ to the score of $1, C$ to the score of 2 , and $D$ to the score of 3 . In each scale from a score of 6 and above and a total of a score of 22 and above indicates pathological symptoms. This questionnaire provides information about medical ailments and disorders and how the general health of the elderly has been over the past month to date. The Mini-Mental State Exam (MMSE) Questionnaire examines psychological problems and various cognitive functions in the elderly and provides an overview of the subject's cognitive status; This exam consists of 3 items of 5 points - each item is 5 questions of 1 point -, 3 items of 3 points, one item of 2 points and 4 items of 1 point and the maximum score of this questionnaire is 30 , the higher score indicates lower disease disorder (11). The Edmonton Questionnaire measures the frailty elderly syndrome; Deficiencies assessed include disability, disease, physical and cognitive disorders, psychosocial risk factors, and elderly syndromes (e.g., falls, delirium, and urinary incontinence). This questionnaire has 9 scales (cognition, general health status, functional independence, social support, medication use, nutrition, mood, continence and functional performance) and all questions have 3 choices, choice 1 has zero points; choice 2 has 1 point and choice 3 has 2 points. The overall score of this questionnaire is between 0 and 17, with a score of 0-5 indicating frailty, 6-8 indicating the vulnerability of the elderly, 8-9 indicating weak frailty, 10-11 indicating moderate weakness and 12-17 indicating severe frailty (12). Before completing the questionnaires, demographic information (age, sex, type of underlying disease, elderly living conditions, marital status, type of insurance, level of education) were collected from the elderly person or the elderly person after obtaining informed oral consent. Validity and reliability of the questionnaires have been done (13-15).

Statistical tests: Descriptive statistics (frequency and percentage for qualitative data), mean and standard deviation were used for quantitative data and according to the type of variables, statistical tests of Chi-square, MannWhitney, Kruskal-Wallis and linear regression tests were used. In order to investigate the relationship between dependent variables (general health, cognitive disorders and frailty elderly) and age, linear regression, dependent variables and gender were used; for place of residence, Man-Whitney, dependent variables and education, type of insurance, marriage, types of underlying diseases of Kruskal- Wallis and Chi-square were used. The significance level of $(P<0.05)$ was considered for the tests and the software used in this study is SPSSv.24.

\section{RESULTS}

This study was performed on 267 elderly people referring to educational hospitals (Imam Khomeini and Mostafa Khomeini hospitals) in llam city in 2020. The mean (standard deviation) age of these patients is (7.5) 71.4, which is 71.1 (7.3) and 71.9 (7.8) for men and women, respectively. $57.7 \%$ of the samples are men and the rest are women. In terms of marital status, the highest and lowest percentages are related to married people (76\%) and single people $(0.7 \%)$, respectively. In terms of education, $2.6 \%$ of the subjects have a university education (lowest) and $47.6 \%$ have a middle school diploma (highest). In terms of insurance services coverage, the highest coverage is related to Salamat Insurance (32.6) and the lowest coverage is related to other groups (18). Other demographic characteristics are detailed in Table 1.

The data obtained from the GHQ-28 questionnaire show that the mean (standard deviation) of the general health score of the elderly is 44.38 (13.43) and this index is more influenced by psychological factors (dimension of depression and anxiety). $44.6 \%, 43.1 \%$ and $10.5 \%$ of the elderly suffer from moderate, mild and severe morbidities, respectively, and only $1.09 \%$ of the elderly do not have any morbid disorders (Table 2). Using linear regression, no significant relationship was found between the age of the subjects and their general health score $(p=0.73)$. Despite the observed difference in the mean score of general health in men and women, no statistically significant relationship was seen between men and women $(p=0.54)$ (Table 4).

The data obtained from the MMSE questionnaire show that the mean and standard deviation of the scores of cognitive disorders were 23.40 and 6.49 , respectively, and ranged from 3 to 30 , and given that the cut-off point for diagnosing cognitive disorders in the elderly was the score less than $24(x<24)$, the prevalence rate of this disorder in the study samples was estimated to be $27.71 \%$ (74 people) and 193 people $(72.28 \%)$ did not have any pathological symptoms.

The data obtained from the Edmonton questionnaire show that the mean and standard deviation of the total score of frailty elderly syndrome were estimated to be 9.29 and 2.98 , respectively where the highest frequency (28.83) was related to the category of severe frailty elderly syndrome and the lowest percentage was related to the category of without frailty elderly syndrome and vulnerable, mild and moderate categories also included $16.10 \%$, $19.85 \%$ and $21.72 \%$ of the samples under study (Table 3 ). 
Based on the results of linear regression, a significant relationship was found between age and cognitive disorder in the elderly, so that on average, for each year of age increase, the rate of cognition in the elderly decreases by 0.62 units, and therefore age has a direct linear relationship with cognitive disorder in elderly over 60 years $(P<0.001)$. Based on the results of linear regression, there was a positive relationship between education and cognitive disorder in the elderly, so that on average, for each level of education, 3.35 units is added to the level of cognition in the elderly. The education variable, as expected, has an inverse linear relationship with cognitive disorder in the elderly over 60 years of age, which is also statistically significant $(p<0.0001)$. No significant relationship $(p=$ 0.54) was seen in the mean (standard deviation) of the total score of elderly cognitive disorder in people who had Tamin Ejtemaei Insurance, Salamat Insurance, Artesh Insurance, Khadamat Darmani Insurance or other insurances. This means that there is no difference between the average total score of cognitive disorder in the study population with different health insurance.

According to the findings, only 65 patients (25.46\%) of the study sample did not have any underlying disease and the rest suffered from at least one of the underlying problems and diseases, among which, cardiovascular diseases with 85 patients $(31.83 \%)$ had the highest frequency and then chronic kidney diseases with a frequency of 30 people (11.23\%) are in the second rating, cancers and diabetes with a frequency of 14 (5.24\%) have equally, the highest rating, the lowest frequency was related to chronic pulmonary diseases, which accounted for $1.12 \%(n=3)$ of the samples. A statistically significant relationship was found between cognitive disorders in the elderly with degenerative diseases $(\mathrm{OR}=0.94,95 \% \mathrm{Cl}$ $(0.89,0.99))$ and eye diseases $(\mathrm{OR}=4.58,95 \% \mathrm{Cl}(1.06$, 19.71)). Table 5 shows the results of examining the relationship between cognitive disorders and gender, marital status and place of residence.

After linear regression, a positive correlation was found to examine the relationship between age and frailty elderly syndrome, so that for each year of age increase, 0.23 units is added to the overall score of frailty elderly syndrome under study $(p<0.001)$. Also, with increasing the level of literacy of the elderly, their frailty decreases significantly ( $p<0.001$ ). Mean (standard deviation) of the overall score of the frailty elderly syndrome was observed in people who had Tamin Ejtemaei Insurance, Salamat Insurance, Artesh Insurance, Khadamat Darmani Insurance or other insurances $(p<0.001)$. Thus, people who were covered by Khadamat Darmani Insurance had the highest rate of frailty elderly and people who were covered by Tamin Ejtemaei Insurance had the lowest rate of frailty elderly. There is a statistically significant relationship between the general status of the underlying disease (yes / no) and the score of frailty elderly syndrome. After the onset of the disease, it was determined separately that the observed difference was related to cardiovascular disease and visual problems in that these patients are more at risk of frailty elderly syndrome than others. Table 4 shows the results of examining the relationship between old age and gender, marriage, place of residence and type of insurance.

\section{DISCUSSION}

According to the results of the present study, the overall general health score of the elderly was $44.38 \pm 13.43$. According to the GHQ-28 classification, only $5(1.9 \%)$ of the elderly in the study had no morbid symptoms and the rest had some degree of disorder in the general health. In a study conducted in Lar city in Fars province (16), this number was $62 \%$ and a similar study in Shahrekord and Sabzevar, close to $57 \%$ and $50 \%$ of the studied elderly did not have good general health $(17,18)$. Despite the high level of public health disorders in the studies mentioned, the difference between the present study and other cases can be attributed to the characteristics of the subjects, as in the studies of others, general population or the elderly referring to health centers were often used, but in the present study, a questionnaire was completed for the elderly referring to Imam Khomeini and Mostafa Khomeini Hospitals, which led to overestimation of the results. However, according to many studies conducted in developed and developing countries, these figures are much lower than the statistics available in the country. For example, in the results of similar studies in France, Germany, Lebanon and China, the calculated numbers for general health disorders were reported as 18.4, 9.1, 16.9 and $4 \%$, respectively (19), which is one of the factors influencing this significant difference, can be the socioeconomic situation, the level of access to health services, per capita national income and, consequently, the income of individuals, and in addition to all these issues, the impact of comprehensive sanctions on the country, one of the most important aspects of which is lack of easy access to medicines and medical equipment, can be mentioned.

Findings of this study showed that out of 267 elderly people referring to educational hospitals in Ilam, 27.1\% (74 people) are suspected of cognitive disorders. This index for Khorramabad cities was calculated to be $81 \%$, which despite being the same average age of participants, is much higher than the present study (6). Arsalani et al. in a study estimated the rate of cognitive disorder in Semnan to be $54.2 \%$, while the samples were collected from the general population of Semnan (20). In another study in Hamedan, this index was mentioned by about $46 \%$, which in all cases the figures are higher than the study. In the study by Hazard (21), 35\% of the elderly had cognitive disorder, which is almost similar to the results of this study.

The prevalence percentage of cognitive disorder, which was calculated through the MMSE questionnaire, was estimated at $27.7 \%$ for the present study, so that $72.4 \%$ of the elderly in the study had no disorder or were in a mild category, which is almost consistent with the results of Arsalani et al. in Semnan (20). Considering that the mean and standard deviation of the cognitive disorder score in a study in China seems to be $27.89 \pm 0.93$, which is more favorable in terms of cognitive disorder than other studies and is consistent with the present study. In a study by Hazard et al., the average incidence of personality disorders in the elderly was estimated at 35\% (21). In the study of Lee et al. in China and Nejati et al. in Iran, the prevalence of cognitive disorders in the elderly was estimated to be $43 \%$ and $55 \%$, respectively, which is much higher than the results of the present study $(22,23)$. 
According to the findings of the study, it seems that the presence of cognitive disorder in the present study is less than other studies. As one of the most important reasons for this difference, the lower average age of the elderly in the present study compared to some other studies as well as the sample selection method can be mentioned. As in the present study, the elderly referring to educational hospitals in llam were used randomly; however, in some other studies, elderly people living in nursing homes were used to calculate the prevalence of cognitive disorders, which may be significantly different from the general population, both physically and mentally. On the other hand, it seems that due to the culture and customs of the people of Ilam and the lack or absence of nursing homes in many cities of the province due to social stigma, the elderly are highly supported by those around them. This can also be one of the possible reasons for this difference in the rate of cognitive disorders.

According to the present study, $13.48 \%$ of people were in a very good condition in terms of frailty elderly syndrome and the rest of the people had some degree of frailty syndrome in such a way that $28.83 \%$ had the highest form of frailty elderly. Similar studies are very different in the United States (16\%) and Japan (16\%) (24). In another review study, this index was estimated to be 10.7 for about 21 studies, which due to the industrial nature of these cities, low average age, changes in the way of reporting contact cases, these changes can be ignored $(25,26)$.

In general, the level of general health in the studied elderly was low, as most of the elderly suffered from mild symptoms, which had the greatest impact on reducing general health in the elderly related to depression and then anxiety (mental dimension). Regarding cognitive disorders, a large number of patients did not have any pathological disorders. The rate of frailty elderly syndrome was high in the study population; the rate of frailty also increased with age. It was also higher in women than men, and decreased with increasing level of education.

Considering that rare studies are conducted in the country regarding the study of frailty elderly syndrome and the factors affecting it, it is suggested that similar studies be conducted in other parts of the country with emphasis on the general elderly population.

It is suggested that nutritional parameters such as the level of micronutrients such as vitamin $D$, calcium and iron be considered to evaluate the frailty elderly syndrome and the factors affecting it.
Table 1. Distribution of demographic variables of the studied elderly

\begin{tabular}{|l|l|l|}
\hline Characteristics & Frequency & Percentage \\
\hline Gender & & \\
\hline Male & 154 & 57.7 \\
\hline Female & 113 & 42.3 \\
\hline Marital status & & \\
\hline Single & 2 & 0.7 \\
\hline Bachelor & 203 & 76 \\
\hline Widow & 62 & 23.3 \\
\hline Place of residence & & \\
\hline Urban & 140 & 52.4 \\
\hline Rural & 127 & 47.6 \\
\hline Educations & & \\
\hline Illiterate & 86 & 32.2 \\
\hline Middle school diploma & 127 & 47.6 \\
\hline Diploma & 47 & 17.6 \\
\hline Academic & 7 & 2.6 \\
\hline Type of insurance & & \\
\hline Tamin Ejtemaei & 41 & 15.4 \\
\hline Salamat & 87 & 32.6 \\
\hline Artesh & 63 & 23.6 \\
\hline Khadamat Darmani & 28 & 10.5 \\
\hline Other & 48 & 18 \\
\hline Living conditions of the elderly & & \\
\hline Alone & 0 & 0 \\
\hline With the family & 267 & 100 \\
\hline
\end{tabular}

Table 2. Mean and standard deviation of general health status of GHQ-28 samples

\begin{tabular}{|l|l|l|}
\hline GHQ-28 Questionnaire & Mean & Standard deviation \\
\hline Subscales & & \\
\hline Physical dimension & 11.45 & 3.50 \\
\hline Anxiety dimension & 10.32 & 3.20 \\
\hline Social dimension & 12.64 & 5.00 \\
\hline Depression dimension & 9.98 & 3.56 \\
\hline Overall health score & 44.38 & 13.43 \\
\hline
\end{tabular}

Table 3. Mean and standard deviation of frailty elderly syndrome in the studied samples

\begin{tabular}{|l|l|l|l|}
\hline $\begin{array}{l}\text { Edmonton } \\
\text { questionnaire }\end{array}$ & $\begin{array}{l}\text { frequency } \\
\text { percentage) }\end{array}$ & Mean & $\begin{array}{l}\text { Standard } \\
\text { deviation }\end{array}$ \\
\hline $\begin{array}{l}\text { Overall score of } \\
\text { frailty elderly } \\
\text { syndrome }\end{array}$ & $267(100)$ & 9.29 & 2.98 \\
\hline Desired & & 4.22 & 0.80 \\
\hline Vulnerable & & 6.63 & 0.49 \\
\hline Mild frailty & & 8.47 & 0.50 \\
\hline Moderate frailty & & 10.62 & 0.49 \\
\hline Severe frailty & & 12.71 & 0.74 \\
\hline
\end{tabular}

Table 4. Investigating the relationship between general health, cognitive disorders and frailty elderly in demographic variables

\begin{tabular}{|c|c|c|c|c|}
\hline 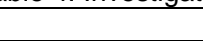 & Variable name & Mean (standard deviation) & Significance & Test \\
\hline \multirow{10}{*}{ General health } & Gender & & \multirow[t]{3}{*}{0.54} & \multirow[t]{3}{*}{ Chi-square } \\
\hline & Male & $46.0(13.4)$ & & \\
\hline & Female & $43.2(13.4)$ & & \\
\hline & Marital status & & & \\
\hline & Bachelor & $67(0.0)$ & $<0.051$ & $\begin{array}{l}\text { Mann- } \\
\text { Whitney }\end{array}$ \\
\hline & Married & $43.5(12.8)$ & & \\
\hline & $\begin{array}{l}\text { Without spouse (widow and } \\
\text { divorcees) }\end{array}$ & $64.4(14.7)$ & & \\
\hline & Place of residence & & 0.47 & $\begin{array}{l}\text { Mann- } \\
\text { Whitney }\end{array}$ \\
\hline & City & $45.02(13.99)$ & & \\
\hline & Village & $43.67(12.80)$ & & \\
\hline
\end{tabular}




\begin{tabular}{|c|c|c|c|c|}
\hline & Education & & \multirow[t]{5}{*}{0.17} & \multirow{5}{*}{$\begin{array}{l}\text { Kruskal- } \\
\text { Wallis }\end{array}$} \\
\hline & Illiterate & $44.91(13.10)$ & & \\
\hline & Middle school diploma & $45.37(13.10)$ & & \\
\hline & Diploma & $40.55(13.91)$ & & \\
\hline & Academic & $45.71(17.17)$ & & \\
\hline & Type of insurance & $43.26(12.16)$ & \multirow[t]{6}{*}{0.43} & \multirow{6}{*}{$\begin{array}{l}\text { Kruskal- } \\
\text { Wallis }\end{array}$} \\
\hline & Tamin Ejtemaei & $43.42(12.86)$ & & \\
\hline & Salamat & $43.41(13.94)$ & & \\
\hline & Artesh & $44.92(13.98)$ & & \\
\hline & Khadamat Darmani & $48.04(14.34)$ & & \\
\hline & Other & $43.26(12.16)$ & & \\
\hline \multirow{10}{*}{$\begin{array}{l}\text { Cognitive } \\
\text { disorder }\end{array}$} & Gender & & \multirow[t]{3}{*}{0.51} & \multirow{3}{*}{$\begin{array}{l}\text { Mann- } \\
\text { Whitney }\end{array}$} \\
\hline & Male & $23.58(6.34)$ & & \\
\hline & Female & $23.17(6.72)$ & & \\
\hline & Marital status & & \multirow[t]{4}{*}{0.002} & \multirow{4}{*}{$\begin{array}{l}\text { Kruskal- } \\
\text { Wallis }\end{array}$} \\
\hline & Bachelor & $27.5(0.71)$ & & \\
\hline & Married & $23.8(6.52)$ & & \\
\hline & $\begin{array}{l}\text { Without spouse (widow and } \\
\text { divorcees) }\end{array}$ & $21.9(6.29)$ & & \\
\hline & Place of residence & & \multirow[t]{3}{*}{0.29} & \multirow{3}{*}{$\begin{array}{l}\text { Mann- } \\
\text { Whitney }\end{array}$} \\
\hline & City & $23.64(6.15)$ & & \\
\hline & Village & $23.14(6.86)$ & & \\
\hline \multirow[t]{16}{*}{ Frailty elderly } & Gender & & \multirow[t]{3}{*}{0.002} & \multirow{3}{*}{$\begin{array}{l}\text { Mann- } \\
\text { Whitney }\end{array}$} \\
\hline & Male & $8.81 \pm 3.07$ & & \\
\hline & Female & $9.94 \pm 2.73$ & & \\
\hline & Marital status & & \multirow[t]{4}{*}{$<0.001$} & \multirow{4}{*}{$\begin{array}{l}\text { Kruskal- } \\
\text { Wallis }\end{array}$} \\
\hline & Bachelor & $8.50 \pm 3.53$ & & \\
\hline & Married & $8.83 \pm 2.98$ & & \\
\hline & $\begin{array}{l}\text { Without spouse (widow and } \\
\text { divorcees) }\end{array}$ & $10.80 \pm 2.46$ & & \\
\hline & Place of residence & & \multirow[t]{3}{*}{0.02} & \multirow{3}{*}{$\begin{array}{l}\text { Mann- } \\
\text { Whitney }\end{array}$} \\
\hline & City & $8.92 \pm 3.10$ & & \\
\hline & Village & $9.69 \pm 2.80$ & & \\
\hline & Type of insurance & $7.4 \pm 3.1$ & \multirow[t]{6}{*}{$<0.001$} & \multirow{6}{*}{$\begin{array}{l}\text { Kruskal- } \\
\text { Wallis }\end{array}$} \\
\hline & Tamin Ejtemaei & $9.2 \pm 2.9$ & & \\
\hline & Salamat & $9.4 \pm 2.6$ & & \\
\hline & Artesh & $10.9 \pm 2.4$ & & \\
\hline & Khadamat Darmani & $9.9 \pm 3.1$ & & \\
\hline & Other & $7.4 \pm 3.1$ & & \\
\hline
\end{tabular}

\section{REFERENCES}

1. KARAMI MB. Ageing in Iran in 1410, a warning to health care system. 2013.

2. Cowin LS, Johnson M. Many paths lead to nursing: factors influencing students' perceptions of nursing. International nursing review. 2011;58(4):413-9.

3. Nobahar M VA. Evaluation of sleep disorders in the elderly and ways to deal with them. Journal of Elderly Research. 2007;2(2):263-8.

4. Cagatay AA, Tufan F, Hindilerden F, Aydin S, Elcioglu OC, Karadeniz $A$, et al. The causes of acute fever requiring hospitalization in geriatric patients: comparison of infectious and noninfectiousetiology. Journal of aging research. 2010;2010.

5. https://www.amar.org.ir/

6. MIRZAEI M, SEPAHVAND E, SAHAF R, MIRZAEI S, PAKDEL A. The prevalence of cognitive impairment in elderly nursing home residents. 2017.

7. Shaheen M, Puri S, Tandon N. An Overview of Frailty in Elderly. Journal of the Indian Academy of Geriatrics. 2016;12(2).

8. Borges MK, Canevelli M, Cesari M, Aprahamian I. Frailty as a predictor of cognitive disorders: a systematic review and meta-analysis. Frontiers in medicine. 2019;6:26.

9. Trowbridge ER, Kim D, Barletta K, Fitz V, Larkin S, Hullfish $\mathrm{KL}$. Prevalence of positive screening test for cognitive impairment among elderly urogynecologic patients.
American Journal of Obstetrics and Gynecology. 2016;215(5):663. e1-. e6.

10. Nejati V, Izadi-najafabadi S, Shoja O, Javadi M, Rezaei F. Cognitive and general health status in elderly with and without history of falling. Iranian Journal of Ageing. 2013;8(1):7-15.

11. Seyedian $M$, FALAH $M$, NOUROUZIAN M, NEJAT $S$, Delavar A, Ghasemzadeh H. Validity of the Farsi version of mini-mental state examination. 2008.

12. Xue Q-L. The frailty syndrome: definition and natural history. Clinics in geriatric medicine. 2011;27(1):1.

13. Malakouti SK, Fatollahi P, Mirabzadeh A, Zandi T. Reliability, validity and factor structure of the GHQ-28 used among elderly Iranians. International Psychogeriatrics. 2007;19(4):623.

14. Foroughan M, Jafari Z, Shirin BP, Ghaem MFZ, RAHGOZAR $M$. Validation of mini-mental state examination (MMSE) in the elderly population of Tehran. 2008.

15. Khalili Parapary $\mathrm{Y}$, Heidarzadeh M, Mozafari N. Translation and Psychometrics of Edmonton Symptom Assessment Scale. Journal of Health and Care. 2017;19(3):136-46.

16. Maghsoudi A, Dindarloo S, Jamali T, Ghaed S, Rastgoo Z, HASSANIPOUR AS. Comparison of sleep quality and general health in elderly individuals living in their houses and nursing homes. 2016.

17. Mortazavi S EaH, Kazem M, Daralibani R. Mental health of the elderly in Shahrekord and its relationship with demographic and social factors. 
18. Zarei M, Abozadeh getabi, Ghanbari moghadam A. A study of the general health status of the elderly in Sabzevar and related factors in 2016. Journal of Gerontology. 2017;2(2):26-33.

19. Kessler RC, Ustun TB. WHO Survey of Prevalence of Mental Health Disorders—Reply. Jama. 2004;292(20):2467-8.

20. Arsalani N, Nobahar M, Ghorbani R, Kia N, Etemadi M. Cognitive disorders and some associated social factors in elderly pepole. Koomesh. 2018:240-7.

21. Hazzard W. Principles of geriatric medicine and depression in old age. New York: McGraw Hill; 2002.

22. Nejati $\mathrm{V} A \mathrm{H}$. Investigating the relationship between cognitive disorders and depression in the elderly. Journal of Elderly Research. 2007;1(2):112-8.
23. Li M, Gao Y, Cui J, Li Y, Li B, Liu Y, et al. Cognitive impairment and risk factors in elderly people living in fluorosis areas in China. Biological trace element research. 2016;172(1):53-60.

24. Chang C-I, Chan D-C, Kuo K-N, Hsiung CA, Chen C-Y. Prevalence and correlates of geriatric frailty in a northern Taiwan community. Journal of the Formosan Medical Association. 2011;110(4):247-57.

25. Sathasivam J, Kamaruzzaman SB, Hairi F, Ng CW, Chinna $\mathrm{K}$. Frail elders in an urban district setting in Malaysia: multidimensional frailty and its correlates. Asia Pacific Journal of Public Health. 2015;27(8 suppl):52S-61S.

26. Badrasawi M. Nutritional, physical and cognitive status among pre-frail and frail Malaysian older adults. 2016. 